\title{
PERCEPTION OF STUDENTS AND TEACHERS REGARDING ACADEMIC FAILURE OF UNDERGRADUATE MEDICAL STUDENTS IN LAHORE, PAKISTAN: A QUALITATIVE EXPLORATORY INVESTIGATION
}

\author{
Gul Muhammad Shaikh', Rabia Khan², Rehan Ahmed Khan ${ }^{3}$, Rahila Yasmeen ${ }^{4}$ \\ ${ }^{1}$ Department of Health Professions Education, National University of Medical Sciences, Rawalpindi, ${ }^{2 W A P D A}$ \\ Hospital Tarbela Dam, Haripur, ${ }^{3}$ Department of Surgery, Islamic International Medical College, Rawalpindi, \\ ${ }^{4}$ Department of Medical Education, Riphah International University, Rawalpindi, Pakistan
}

\begin{abstract}
Background: Academic failure adds extra pressure to emotional intelligence of students and this may lead to psychological disturbance. The objective of this study was to explore perception of students and teachers regarding academic failure of undergraduate medical students in Lahore, Pakistan.

Materials \& Methods: This qualitative exploratory study was conducted at Department of Medical Education, University College of Medicine and Dentistry, University of Lahore, Pakistan from January 2018 to October 2018. Sample included nine MBBS students who took their last examination in year 2017 and five teachers, all from University College of Medicine and Dentistry, University of Lahore. Sampling was purposive. These nine students included five who graduated without failure and four who experienced two/more failures. Medical students were interviewed via two focus groups, whereas face to face semi-structured, audio-recorded interviews were done for teachers. Interview questionnaires were designed on basis of attribution theory. The fundamental question of study was "What are the reasons behind undergraduate medical students' failure in annual examination?" with five more questions. The interviews were transcribed in English and sent back to participants for member checking. The interviews were organized in ATLAS.ti software for thematic analysis based on Weiner's Attribution Theory. Open coding was done after familiarization of data, leading to formation of categories, sub-themes and themes related to our conceptual framework.
\end{abstract}

Results: 160 open codes were condensed to 35 axial codes leading to two themes. Main reasons for students' failure in examinations perceived by both students and teachers were lack of ability, lack of effort and lack of motivation. Additionally, the students attributed bad luck to academic failure. Other factors included were teachers' related factors, curriculum related factors and negative students' attitude.

Conclusion: Medical institutions must take into account reasons for academic failure among medical students and address those issues to improve their performance.

KEY WORDS: Academic Failure; Medical Students; Medical Education; Focus Groups; Curriculum; Faculty; Motivation; Attitude; Pakistan.

Cite as: Shaikh GM, Khan R, Khan RA, Yasmeen R. Perception of students and teachers regarding academic failure of undergraduate medical students in Lahore, Pakistan: a qualitative exploratory investigation. Gomal J Med Sci 2020 Apr-Jun; 18 (2):54-8. http://doi.org/10.46903/gjms/18.02.826

\section{Corresponding Author:}

Dr. Gul Muhammad Shaikh

Assistant Professor, Department of Health Professions

Education, National University of Medical Sciences,

Rawalpindi, Pakistan

E-mail: shaikhgul@hotmail.com

Date Submitted: $\quad 04-01-2020$

Date Revised: $\quad 10-05-2020$

Date Accepted: $\quad 01-06-2020$

\section{INTRODUCTION}

1.1 Background: Medical education aims at improving students' learning, making them successful in all professional domains through formative and summative examinations. Recently traditional systems are being replaced by integrated systems to inculcate self-directed learning in students. This autonomy in learning can give confidence to the students but also brings drastic negative effects if the student 
does not succeed in his/ her exam. ${ }^{1}$ Hence, despite such innovations, there is a significant rate of failure of medical students in examinations. ${ }^{2}$

Academic failure also adds extra pressure to emotional intelligence of students and this may lead to psychological disturbance and stress. ${ }^{1}$

On the other hand, success in annual examinations relieves burden from the student's shoulders. Success is linked to positive outcomes that are essential for academic as well as practical life; such as being organized, punctual and prepared with a plan for a task. $^{3}$

Failure impacts medical students in negative ways. An experience of failure impairs expectation of good results, provokes negative thoughts and inculcates fear for next examinations. ${ }^{4}$ Atkinson et, al. ${ }^{5}$ argued in his theory of "Risk Taking Behavior" that as a result of failure, an individual feels embarrassed, and avoids the task completely in order to avoid failure. Failure in examinations induces negative thoughts and demotivation among students. Haglind, et al. ${ }^{1}$ observed that most common effect of failure is emerging of negative vibes. In contrast, student who takes failure as a challenge, and improves his/ her flaws with self-efficacy, self-belief, self-assessment and self-regulation reveals good performance in examinations after failure. ${ }^{6}$ On the other hand, Yadav, et al. ${ }^{7}$ observed that self-confidence decreases with each failed attempt and illustrated in his study, that students starts showing negative attitude towards the subject in which they fail.

Those students, who get demoralized and demotivated with experience of failure, need help and mentoring. They need to be guided to a right direction, mentoring and counseling, so that they can achieve a better life after graduation. On taking account of one's action, Edward Counsel discussed that, "Reasons are the pillars of mind".

1.2 Rationale \& Significance: Hence in order to develop a strategy to support such medical students who experience academic failure, it is imperative to explore the reasons behind failure among medical students, which have been merely described in Pakistan.

1.3 Objective: The objective of this study was to explore the perception of students and teachers regarding academic failure of undergraduate medical students in Lahore, Pakistan.

\section{MATERIAL AND METHODS}

2.1 Design, Setting \& Duration: This qualitative exploratory study was conducted at the Department of Medical Education, University College of Medicine and Dentistry, The University of Lahore, Lahore, Pakistan from January 2018 to October 2018.

2.2 Sampling: The sample included nine MBBS students who took their last examination in the year
2017 and five teachers, all from University College of Medicine and Dentistry, The University of Lahore, Lahore, Pakistan. Sampling technique was purposive non-probability.

These nine students from MBBS program included five who graduated without failure and four who experienced two or more failed attempts.

\subsection{Conduct of Procedure \& Data Collection}

Plan: Participants underwent semi-structured, audio-recorded interviews. Medical students were interviewed via two focus groups, whereas face to face interviews were done for the teachers. Interview questionnaires were designed on the basis of Attribution Theory.

Open-ended questions were used in the interviews. The fundamental question of the study was "What are the reasons behind undergraduate medical students' failure in annual examination?" For probing, further questions were asked to find out reasons for academic failure.

There were six questions each for students and teachers. After peer review and pilot testing, the participants were approached, explaining to them the rationale of the study. Participation was voluntary, anonymous and informed consent was taken. The interviews were transcribed in English language and sent back to the participants for member checking (respondent validation) before data analysis.

2.4 Data Analysis Plan: The interviews were organized in ATLAS.ti software (Scientific Software Development $\mathrm{GmbH}$, Berlin, Germany) for analysis. Thematic analysis was done, based on Weiner's Attribution Theory. Open coding was done after familiarization of data, leading to formation of categories, sub-themes and themes related to our conceptual framework.

\section{RESULTS}

3.1 Demographics: The sample of 14 participants included nine students and five teachers. Nine students included five boys and four girls of 23-25 years age. These included five who graduated without failure and four who experienced two or more failed attempts.

Five teachers included four men and one women, with one having 5-6 years teaching experience, three 7-10 years and one having more than 10 years' experience. This sample included one assistant professor, two associate professors and one professor.

3.2 Qualitative Analysis: Weiner, et al. ${ }^{8}$ (1986) explained in his Attribution Theory that students attribute their success and failure to four major factors. Figure 3.2 describes the concept of attribution theory of Weiner in a very precise way. Ability, task difficulty, luck and effort are the major factors which are responsible for failure and success of students. 


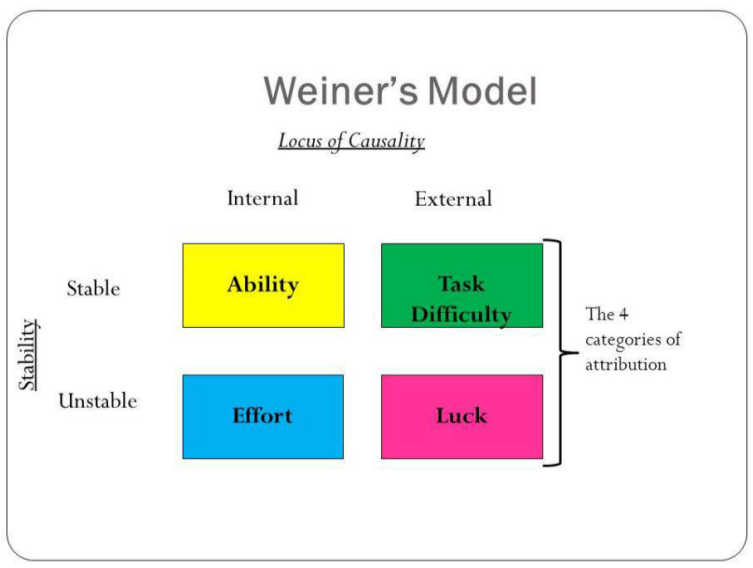

Figure 3.2: Weiner's Attribution Theory Model

Initially 163 open codes were condensed to 35 axial codes merging into two main themes taking attribution theory as conceptual framework of the study. Table 3.2 shows hierarchy of themes and subthemes identified.

\section{DISCUSSION}

4.1 Distractions: Environment also influences the success and failure of a student. ${ }^{9}$ Almost all of the interviewees have agreed to one common sentence "distraction leads to failure". There could be many distractions in the form of social circle or crisis, financial problems, bad company, psychological trauma due to loss of loved one and home sickness in hostilities.

4.2 Lack of ability: Heider characterized any "action outcome" as dependent upon "blend of successful individual and environmental abilities". He documented that "People exhibit stable psychological qualities that decide their intentions to conduct a task". ${ }^{10}$

Students reported that they were not able to attempt the paper correctly and some students added that they could not elaborate their concepts in viva, that's why they failed. Students should work on their writing as well as communication skills. This

Table 3.2: Themes and subthemes in the study of perception of students and teachers regarding academic failure of undergraduate medical students in Lahore, Pakistan $(n=14)$

\begin{tabular}{|c|c|c|}
\hline Themes & Sub-themes & Contents of sub-themes \\
\hline \multirow{12}{*}{$\begin{array}{l}\text { Perception of students } \\
\text { regarding academic } \\
\text { failure }\end{array}$} & \multirow{4}{*}{ Behavioral flaws } & Lack of ability \\
\hline & & Lack of effort \\
\hline & & Lack of intrinsic motivation \\
\hline & & Bad luck \\
\hline & \multirow{3}{*}{ Curriculum related factors } & Cognitive overload \\
\hline & & Clarity of curriculum \\
\hline & & Orientation of curriculum \\
\hline & \multirow{3}{*}{ Teachers' related factors } & Teachers' availability \\
\hline & & Teachers' support \\
\hline & & Teachers' training \\
\hline & \multirow{2}{*}{ Other factors } & Distractions \\
\hline & & Lack of resources \\
\hline \multirow{11}{*}{$\begin{array}{l}\text { Perception of teachers } \\
\text { regarding academic } \\
\text { failure }\end{array}$} & \multirow{3}{*}{ Behavioral flaws } & Lack of ability \\
\hline & & Lack of effort \\
\hline & & Lack of intrinsic motivation \\
\hline & \multirow{3}{*}{ Curriculum related factors } & Cognitive overload \\
\hline & & Disoriented curriculum \\
\hline & & Lack of clarity in curriculum \\
\hline & \multirow{2}{*}{ Teachers related factors } & Teachers' availability \\
\hline & & Teachers' training \\
\hline & \multirow{3}{*}{ Other factors } & Attitude of students \\
\hline & & Distractions \\
\hline & & Institutional policies' induced risks \\
\hline
\end{tabular}


research extracted the inability to write and speak properly, to be the reason of failure. Teachers and students talked about low stake assessments and its importance in reinforcement of knowledge and practice of tests. This practice improves student's writing and communication skills. Dunlosky, et al. ${ }^{6}$ said "for improvement of learning of students and reinforcement of study material or learning objectives, tests should be taken again and again". Some students stated that, haphazard studies also lead to failure. Organization of learning strategy could lead to quality learning.

4.3 Lack of effort: One teacher professed "students want spoon feeding". Students copy the notes of teachers without doing effort to understanding the concept. Spoon feeding lectures should be avoided by conducting interesting tasks among students to engage students in active learning and constructing concepts in their mind. ${ }^{11}$ Another reason stated by the teachers and students of not making concepts of study was cramming. Cramming and unplanned study leads to failure. ${ }^{12}$

4.4 Lack of intrinsic motivation: The most common reason for lack of intrinsic motivation found by the research was "being forced by parents/ family to take admission in medical college". As reported in a study, that students attributed that they were pushed to the course by their parents/ families and thus they do not like to study the subject and they fail. ${ }^{13}$

Tasks, that includes student's participation, increases learning and motivation to learn. ${ }^{14}$ Self-directed learning (SDL) is very essential component of success. Teachers in the interviews said that students do not visit library in SDL period. To resolve this issue, check should be kept on students, but literature defends that SDL does not mean to keep a check on students. It depends on students, how do they organize their method of learning and gaining knowledge..$^{15}$ SDL increases one's competencies with respect to skill and knowledge. ${ }^{16}$

4.5 Luck: Students believe in luck to be a reason of failure in examination but teachers did not agree to this statement. The external factor for success could be luck or being liked by the teacher. ${ }^{17}$

\subsection{Curriculum related factors}

Curriculum is the focus of school's policies with students' education being the target. It is the set of educational strategies that is used by the education providing system. Students should prepare the complete syllabus according to learning objectives of curriculum. Sometimes students prepare selective topics for examinations, simultaneously ignoring other topics, which may be important for success. ${ }^{18}$

Goals of the curriculum should be explained clearly and those goals should be in competition with other medical colleges as well, so that the graduated students prove to be competent for the society as well. ${ }^{19-21}$ Students may experience conflict with teachers or class fellows that lead to depression, thus causing failure. ${ }^{22}$

4.7 Limitations: There was limited number of students and teachers in our study, because only few teachers and students agreed to give interviews. My study included sample from the University College of Medicine, University of Lahore, Lahore, Pakistan, so it cannot be inferred to all medical and dental students. There could be some other reasons of failure at different institutes and in different regions of Pakistan.

4.8 Future research: Now that the problem has been explored, future directions could be to conduct study on larger scale to find reasons of failure among medical and dental students in Pakistan, by taking sample from different institutes in different regions of Pakistan. This project can also give rise to study on qualities and habits of students which may lead to success/ failure in medical and dental colleges.

\section{CONCLUSION}

As dealing with human life demands high amount of motivation, knowledge and management, it is important for students to have clear goals and orientation upon joining professional colleges. Traditional learning has shifted to student centered and self-directed learning. Teachers' support can guarantee a good educational and learning experience for medical students. Medical institutions must take into account the reasons for academic failure among medical students and address those issues, where possible in order to improve performance of medical students in future and uplift quality of education provided.

\section{REFERENCES}

1. Haglind D. Coping with success and failure: $A$ qualitative study on athletes and coaches in track and field [thesis]. Halmstad, Sweeden: Halmstad University; 2003.

2. MBBS examination: $84.7 \%$ of the students pass. The Express Tribune [serial online]. 2014 Jan 25 [cited 2019 Aug 12]. Available at: https://tribune. com.pk/story/662982/mbbs-examination-84-7-ofthe-students-pass

3. Regier J. Why is academic success important? Saskatchewan School Boards Association. Available at: https://saskschoolboards.ca/wp-content/ uploads/2015/08/2011SIAST.pdf

4. Brunstein JC, Gollwitzer PM. Effects of failure on subsequent performance: the importance of self-defining goals. J Pers Soc Psychol 1996; 70(2):395-407. https://doi.org/10.1037/00223514.70.2.395

5. Atkinson JW. Motivational determinants of risk-taking behavior. Psychol Rev 1957; 64(6, Pt. 1):359-72. https://doi.org/10.1037/h0043445

6. Dunlosky J, Rawson KA, Marsh EJ, Nathan MJ, Willingham DT. Improving students' learning with 
effective learning techniques: promising directions from cognitive and educational psychology. Psychol Sci Public Interest 2013 Jan; 14(1):4-58. https://doi.org/10.1177/1529100612453266

7. Yadav M, BaniAta H. Factorizing demotivation, finding motivation: a constructive approach to quality enhancement. Procedia - Soc Behav Sci 2013; 70:120-30. https://doi.org/10.1016/j. sbspro.2013.01.047

8. Weiner B. An attributional theory of achievement motivation and emotion. Psychol Rev 1985 Oct; 92(4):159-90. https://doi.org/10.1007/978-1-46124948-1_6

9. Gülten Genç. Attributions to success and failure in English language learning: the effects of gender, age and perceived success. European J Educ Studies 2016; 2 (12):25-43.

10. Malle BF. Attribution Theories: how people make sense of behavior. Theor Soc Psychol 2011; 72-95.

11. Dent JA, Harden RM, editors. A practical guide for medical teachers. 4th ed. London: Churchill Livingstone; 2013. Available at: http://edomsp. sbmu.ac.ir/uploads/A_Practical_Guide_for_Medical_Teachers.pdf

12. Gould JL. The biology of learning. Annu Rev Psychol 1986; 37(1):163-92. https://doi.org/10.1146/ annurev.ps.37.020186.001115

13. Kathryn P. The effects of self-assessment on academic performance [unpublished thesis]. Baltimore, MD, USA: Goucher College; 1916. Available at: https://mdsoar.org/handle/11603/3084

14. Lesgold AM, Pellegrino JW. Cognitive Psychology and Instruction. 1st ed. Heidelberg Germany: Springer; 1978. https://doi.org/10.1007/978-14684-2535-2_1
15. General Medical Council. Tomorrow's Doctors (2009)

16. outcomes and standards for undergraduate medical education. [cited 2019 Aug 12]. Available at: https://www.gmc-uk.org/-/media/documents/tomorrows-doctors---to-be-withdrawnon-01-01-2016_pdf-62052357.pdf

17. Swanwick T, editor. Understanding medical education-Evidence, theory and practice. 2nd ed. West Sussex, UK: John Willy; 2014. https://doi. org/10.1002/9781118472361

18. Boruchovitch E. A study of causal attributions for success and failure in mathematics among Brazilian students. Interam J Psychol 2004; 38(1):53-60.

19. Berkeley University of California. Overview of learning theories. [homepage on the Internet]. [cited 2019 Aug 12]. Available at: https://gsi. berkeley.edu/gsi-guide-contents/learning-theory-research/learning-overview/

20. Glatthorn A, Boschee F, Whitehead BM, Boschee BF. Curriculum Leadership: Strategies for Development and Implementation; California: Sage; 2012.

21. Al-Eraky MM. Twelve tips for teaching medical professionalism at all levels of medical education. Med Teach 2015; 37(11):1018-25. https://doi.org /10.3109/0142159X.2015.1020288

22. Yelon SL, Ford JK, Anderson WA. Twelve tips for increasing transfer of training from faculty development programs. Med Teach 2014 Nov; 36 (11):945-50. https://doi.org/10.3109/014215 9X.2014.929098

23. Connecticut State Department of Education. Guidelines for Identifying and educating students with serious emotional disturbance. [cited 2019 Aug 20]. Available at: https://portal.ct.gov/-/media/SDE/Publications/edguide/ed_guidelines.pdf

\section{CONFLICT OF INTEREST \\ Authors declare no conflict of interest. \\ GRANT SUPPORT AND FINANCIAL DISCLOSURE None declared.}

\begin{tabular}{|c|c|}
\hline \multicolumn{2}{|c|}{ AUTHORS' CONTRIBUTION } \\
\hline The following authors have made subst & ial contributions to the manuscript as under: \\
\hline Conception or Design: & GMS, RK \\
\hline Acquisition, Analysis or Interpretation of Data: & GMS, RK, RAK, RY \\
\hline Manuscript Writing \& Approval: & GMS, RK, RAK, RY \\
\hline
\end{tabular}

